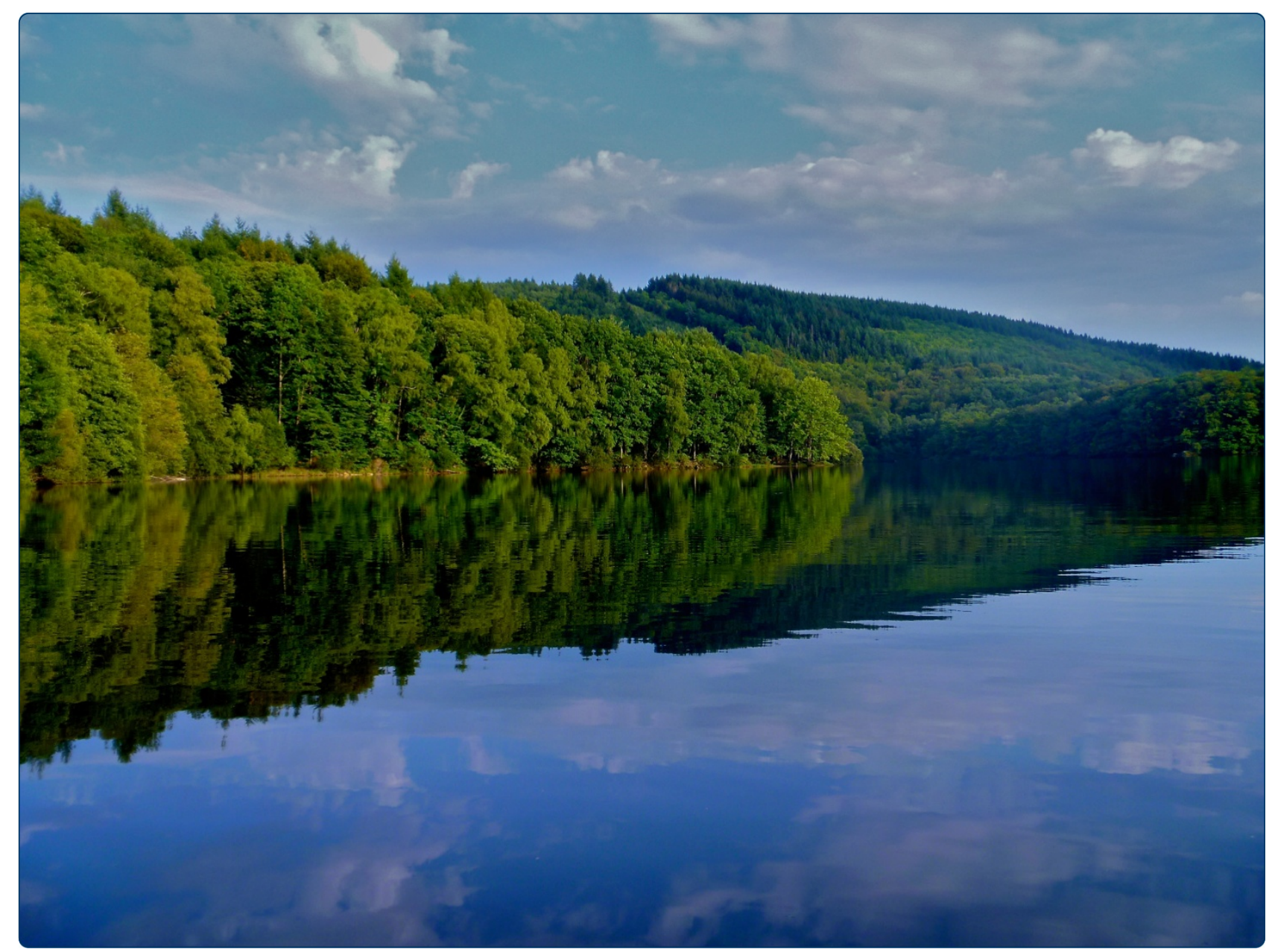

Testing the VEMCO Positioning System: spatial distribution of the probability of location and the positioning error in a reservoir

Roy et al.

( ) Biomed Central 


\title{
Testing the VEMCO Positioning System: spatial distribution of the probability of location and the positioning error in a reservoir
}

\author{
Romain Roy ${ }^{1 *}$, Jeremy Beguin ${ }^{2}$, Christine Argillier ${ }^{2}$, Laurence Tissot ${ }^{1}$, Frank Smith ${ }^{3}$, Stephanie Smedbol ${ }^{3}$ \\ and Eric De-Oliveira'
}

\begin{abstract}
Background: Recent improvements in fixed acoustic monitoring receivers allow the tracking of individual aquatic animals over long periods of time with regular fine-scale positions. The VEMCO Positioning System (VPS) is now widely used, but various methodological issues remain to be clarified. The aim of this study was to analyze the spatial distribution of the probability of location and the positioning error over the entire surface of a hydropower reservoir, prior to analyzing fish behavior.

Findings: Filtering the data set by the horizontal position error (HPE) significantly reduced the positioning error. Retaining only the positions with an HPE less than 15 retained 79\% of VPS positions and decreased the positioning error by $33 \%$ (mean $=3.3 \mathrm{~m}, \mathrm{SD}=3.3 \mathrm{~m}$ ). A higher probability of location was observed inside than outside the receiver array (44\% and 36\%, respectively). Moreover, the positioning error significantly differed inside $(n=243$, mean $=2.4 \mathrm{~m}, \mathrm{SD}=2.1 \mathrm{~m})$ and outside $(n=253$, mean $=4.2 \mathrm{~m}, \mathrm{SD}=4.0 \mathrm{~m})$ the receiver array $(P<0.001)$. Finally, the lowest positioning errors were detected in the area with the highest receiver density.

Conclusions: The VPS measures fish positioning in a reservoir, under suitable conditions, with satisfactory accuracy. We showed that the probability of location and the positioning error differed spatially in accordance with previous results in other conditions. Consequently, these analyses are recommended as a prerequisite to further spatial analyses using VPS-derived data.
\end{abstract}

Keywords: Acoustic telemetry, VEMCO Positioning System, Probability of location, Positioning error, Spatial distribution

\section{Findings}

\section{Background}

Acoustic tracking is becoming an increasingly popular tool for determining activity patterns and habitat utilization by aquatic animals in acoustically amenable environments [1-4]. Recent improvements in fixed acoustic monitoring receivers potentially allow the tracking of a tagged aquatic animal anywhere in the instrumented region of interest, recording individual positions every few seconds [5]. Nevertheless, in spite of its effect on the quality of the

\footnotetext{
* Correspondence: romain.roy@irstea.fr

${ }^{1}$ EDF R\&D, LNHE Departement, HYNES (Irstea - EDF R\&D), 6 Quai Watier, Chatou Cedex 78401, France

Full list of author information is available at the end of the article
}

behavioral data collected, the accuracy of positioning measurements is seldom assessed (but see [6-8]).

The probability of location, defined by the proportion of tag transmissions that result in a calculated position, and the positioning error, that is, the Euclidian distance between the calculated position and the actual position of the tag, are major characteristics of telemetry systems [6]. Various authors have pointed out the effects of multiple intrinsic and environmental factors on the probability of location and positioning error, such as the number of receivers deployed, the accuracy of the receiver location measurements, the receiver array characteristics, collisions between transmissions from multiple tags, the location of the tag relative to the locations of the receivers, time

\section{Biomed Central}


measurement precision at the receivers, the bottom topography and thermal conditions [2,6,8-12].

The VEMCO Positioning System (VPS) is based on a three-receiver time difference of arrival (TDOA) algorithm used by the VEMCO Radio-Acoustic Positioning (VRAP) system $[9,13]$. The VPS has been extended to work with an array of three or more receivers that do not have clocks synchronized to real time $[9,13]$. The VPS can estimate fine-scale positional information on multiple tagged animals simultaneously over a large area [9]. This system is now widely used in fish behavior studies in marine and freshwater environments [7,14-20]. However, its performance has not yet been extensively documented (but see [7]). The aim of this study was to analyze the spatial distribution of the probability of location and the positioning error over the entire surface of a hydropower reservoir, prior to analyzing fish behavior.

\section{Methods}

Bariousses hydropower reservoir is an 80.9-ha impoundment of the Vézère River in west central France $\left(45.33^{\circ} \mathrm{N}\right.$, $1.49^{\circ} \mathrm{E}$ ) (Figure 1). Its shape is irregular and its water level fluctuates. An array of 40 underwater VR2W omnidirectional acoustic receivers (VEMCO, Halifax, NS, Canada) was deployed in January 2012 throughout the reservoir (Figure 1). The number and distribution of receivers was a compromise in terms of cost and the need to instrument the whole reservoir, while seeking to provide full local detection coverage and high precision of estimated locations. The receiver deployment took the bathymetry, the shape of the reservoir and the maximum intensity of water-level fluctuations into account to avoid the potential for receivers being beached. The receivers were positioned an average of $150 \mathrm{~m}$ apart (range was $72 \mathrm{~m}$ to $223 \mathrm{~m}$ ) at an average depth of $6 \mathrm{~m}$ (range was $2 \mathrm{~m}$ to $15 \mathrm{~m}$ ).

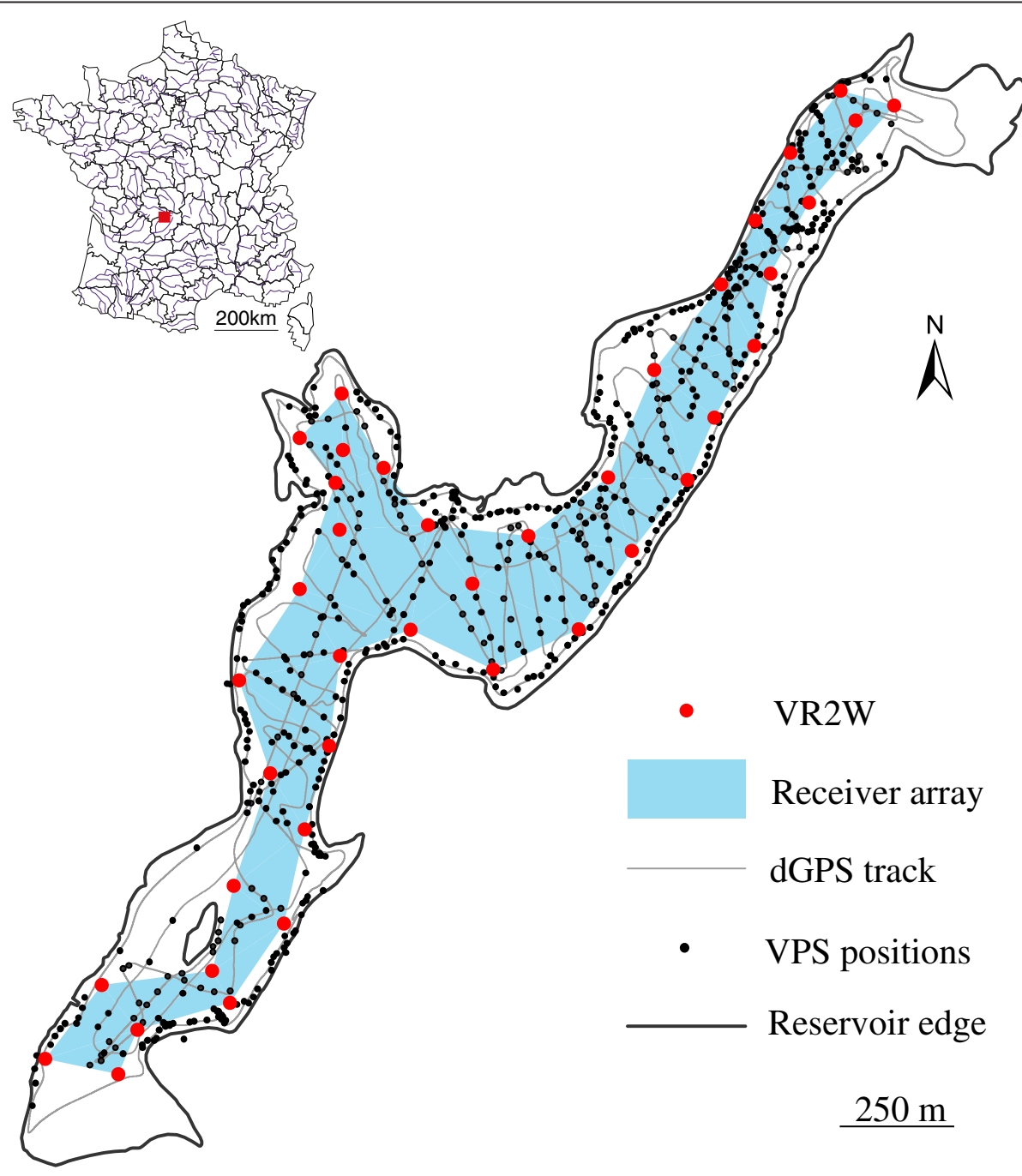

Figure 1 Spatial distribution of the data used for this study. The inset map of France shows the location of the reservoir. The red dots are the positions of the receivers, the blue polygon is the receiver array, the grey lines are the dGPS tracks, the black dots are the VPS positions and the black line is the reservoir's edge. dGPS, differential GPS; VPS, VEMCO Positioning System. 
Moving tests were conducted with a V9P-2L coded tag (69 kHz, actual transmission delay of $25 \mathrm{~s}$, at the start of its operational life) slowly dragged by boat (mean speed was $1.6 \mathrm{~km} \mathrm{~h}^{-1}$ ) at a depth of $1 \mathrm{~m}$. The actual position of the tag was measured every second with a differential GPS (dGPS) (Leica $1200^{\circ}$ ) (Figure 1). It was assumed that the performance of this test tag in terms of sound pressure level was typical of the V9P-2L model. The tests were conducted over three non-consecutive days (26 and 29 January 2012 and 15 January 2013), between 9 am and $5 \mathrm{pm}$, with comparable water temperatures $\left(4.9^{\circ} \mathrm{C}\right.$ to $5.2^{\circ} \mathrm{C}$; thermal profile isothermal) and an unchanged receiver configuration.

The VPS positioning algorithm was used to calculate the positions of the transmissions of the test tag [13]. Because the receivers' clocks are not synchronized with GPS time, to match the calculated and GPS-measured positions accurately, the data needed to be synchronized. For each of the three days of testing, each calculated position was matched with its spatially closest GPS-measured position, and the time differences between the matched positions were averaged for that day. These daily averages were used to correct VPS time to GPS time.

To assess the probability of location, each test tag transmission not positioned by the VPS had to be located; the location of the test tag was obtained from the GPS-measured track of the boat at the precise time when the tag transmitted (every $25 \mathrm{~s}$ ). For transmissions that were positioned by the VPS, the calculated position was used as the location of the test tag. The positioning error was calculated for each calculated position as the Euclidean distance between it and the GPS-measured position with the same time.
The horizontal position error (HPE) was estimated for each calculated position [13]. HPE is a relative and dimensionless measurement of how sensitive a particular calculated position is to error for the measurements of the arrival times of the transmission at the receivers [13]. A calculated position with a higher HPE provides less information on the position of the animal than a calculated position with a lower HPE. Because of this, VPS positions are usually filtered by HPE prior to fine-scale analysis of fish behavior. The changes in the number of calculated positions and the average positioning error were analyzed for different HPE filter values.

The probability of location over the entire surface of the reservoir was interpolated from calculated positions and transmissions not positioned using an inverse distance weighted technique (cell size $=10 \mathrm{~m}$; power $=0.1$; search radius $=$ the ten nearest points) [21]. The positioning error was mapped in the same way as the probability of location.

A Wilcoxon nonparametric test was used to compare the difference in the positioning error inside and outside the receiver array, computed with $\mathrm{R}$ software [22]. Spatial analysis and representations were performed with ArcGIS 10 (ESRI, Redlands, CA).

\section{Results}

In this study, 628 positions were calculated over 8 h 54 min. The average probability of location was $49 \%$ and the average positioning error was $5.0 \mathrm{~m}$ (range $=0.05 \mathrm{~m}$ to $90.4 \mathrm{~m}, \mathrm{SD}=7.8 \mathrm{~m}$ ).

Selecting the positions with an HPE less than 15 decreased the average positioning error by $33 \% \quad(n=496$, mean $=3.3 \mathrm{~m}, \mathrm{SD}=3.3 \mathrm{~m}$ ) (Figure $2 \mathrm{~A}$ ) while still retaining
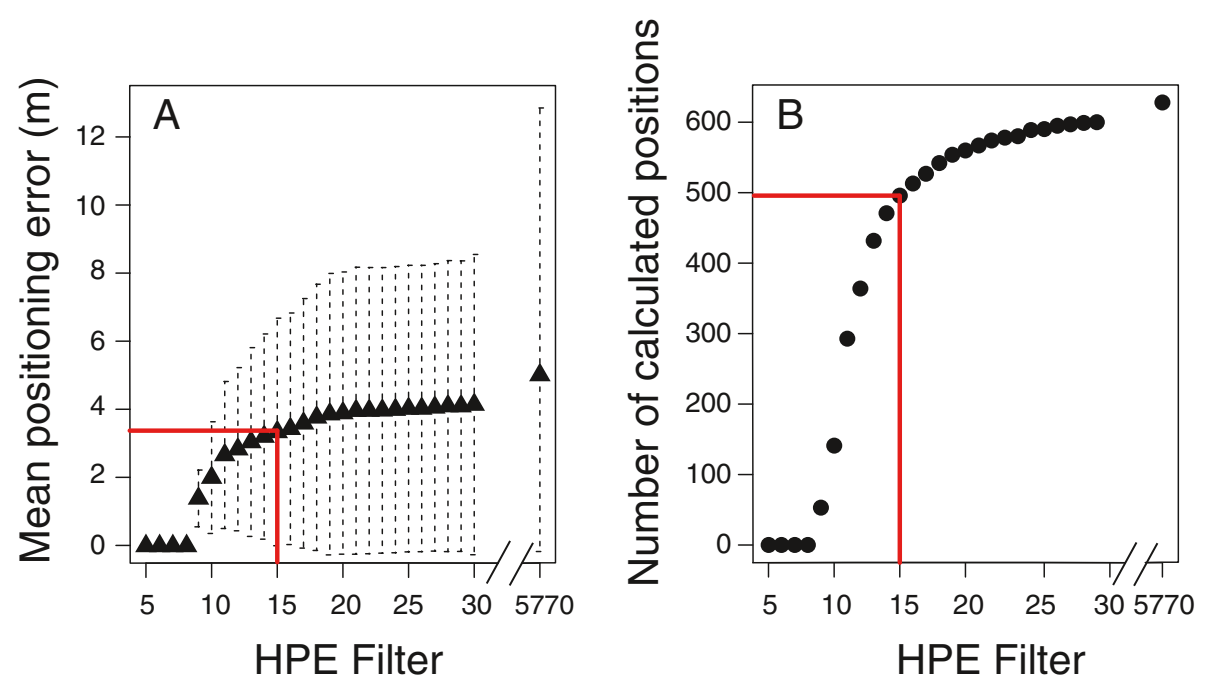

Figure 2 Relation between the mean positioning error (A) and number of calculated positions (B) with the HPE filter values. The dotted lines are the standard deviations (mean \pm SD), and the red lines show the value of 15 for the HPE filter. Note the discontinuity of the $x$-axis; HPE filters between 30 and 5770 (only 28 positions concerned) have not been shown for clarity. HPE, horizontal position error. 
$79 \%$ of the calculated positions (Figure 2B). With this selection, a higher probability of location was observed inside than outside the receiver array (44\% and 36\%, respectively).

Moreover, the positioning error significantly differed inside $(n=243$, mean $=2.4 \mathrm{~m}, \mathrm{SD}=2.1 \mathrm{~m})$ and outside $(n=253$, mean $=4.2 \mathrm{~m}, \mathrm{SD}=4.0 \mathrm{~m})$ the receiver array with filtering $(P<0.001)$ and without filtering $(P<0.001)$.

The spatial interpolation maps confirmed that most of the lowest probability of location sites $(<25 \%)$ and the highest positioning error sites $(>5 \mathrm{~m})$ were located outside the receiver array (Figures 3 and 4). Nevertheless, it can be seen from these maps that there is a positioning error less than $5 \mathrm{~m}$ over most of the reservoir surface and an error less than $2 \mathrm{~m}$ in one-third of the area (the upstream part) where the receiver density was highest (Figures 3 and 4).

\section{Discussion}

This study provides information on VPS performance and highlights the spatial distribution of the probability of location and the positioning error. Currently, positions calculated with the VPS are usually filtered by HPE before biological analysis. Our results confirm the usefulness of this technique in improving the quality of the positioning [7]. In many studies, the HPE threshold is set between 10 and $20[16,17,23,24]$ but this choice is seldom discussed or objectively assessed. In the environmental conditions experienced in this study, we observed a large variability in the number of calculated positions and the mean positioning error for HPE filters between 10 and 20. A value of 15 was used in this study to minimize positioning error (mean $3.3 \mathrm{~m}$ ) as much as possible while not decreasing sample size excessively.

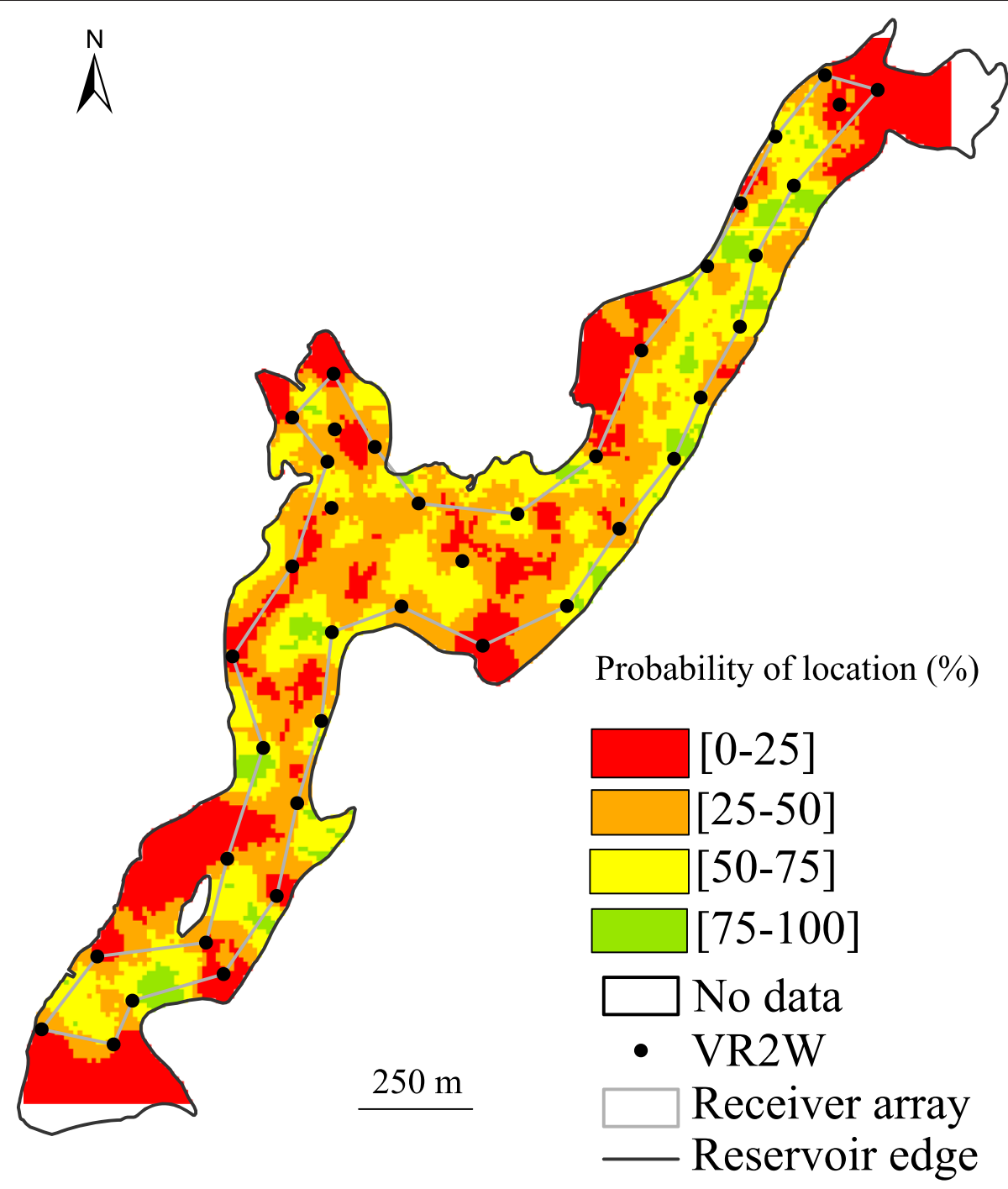

Figure 3 Spatial distribution of the probability of location inside the Bariousses reservoir when selecting the positions with an HPE less than 15. The grey line is the limit of the receiver array, the black dots are the positions of the receivers and the black line is the reservoir's edge. HPE, horizontal position error. 


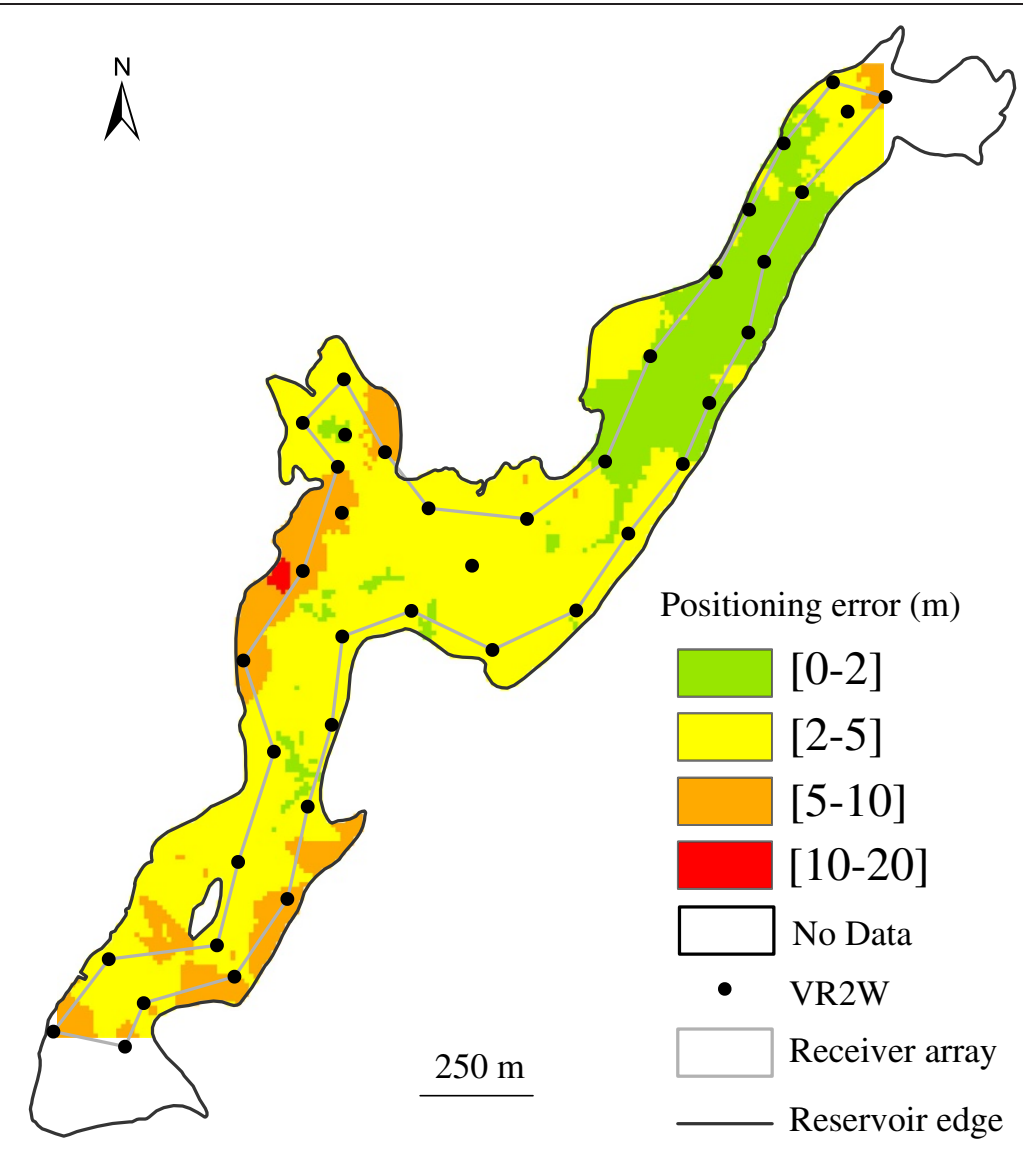

Figure 4 Spatial distribution of the positioning error inside the Bariousses reservoir when selecting the positions with an HPE less than 15. The grey line is the limit of the receiver array, the black dots are the positions of the receivers and the black line is the reservoir's edge. HPE, horizontal position error.

For each study site, located in different environmental conditions, the choice of this threshold value (here a compromise between the number of positions and positioning error) should be discussed according to the objectives of the study.

An average of $40 \%$ probability of location and positioning error of $3.3 \mathrm{~m}$ throughout the Bariousses reservoir when data are filtered by HPE less than 15 are consistent with the values obtained in an estuary by Espinoza et al. [7]. In the environmental conditions experienced in this study, using VR2W receivers and a V9P-2L tag, the probability of location was higher and the positioning error significantly lower inside than outside the receiver array and when more receivers were used for positioning. Therefore, with a more robust data set, we confirm the results of Espinoza et al. [7] regarding the distributions of the probability of location and the positioning error. However, we noted that the probability of location was rather low compared to our expectations. This has to be taken into account before choosing a transmission delay for the tag in accordance with the monitoring frequency desired.
Analyzing the spatial distribution of the probability of location and the positioning error makes it possible to isolate areas where aquatic animals would be detected with difficulty or inaccurately located. The present results demonstrate that in the Bariousses reservoir, fish can be tracked almost continuously with a reasonable positioning error $(<5 \mathrm{~m})$, even near the shores. With a positioning error of less than $2 \mathrm{~m}$ in the upstream part of the reservoir, where the density of receivers was the highest and the receiver array was the most optimal, this equipment can monitor fish habitat use at a fine scale. Nevertheless, the detection efficiency estimates are likely to be at the top end of the range of what can be expected during an actual tracking study because collisions increase when multiple tags are used.

Finally, these tests provide information on VPS performance under suitable conditions and confirm some previous results of the accuracy of the system. This kind of preliminary study could be very useful for the refinement of the array design itself. Additionally, these analyses are recommended as a prerequisite to any further spatial analyses using VPS-derived data. 
To complete this work, a further sample is required in areas with a low probability of location $(<25 \%)$ to refine the spatial distribution of the positioning error. Moreover, reservoirs experience thermal and chemical stratification over the year [25] and fish behavior may be studied over long periods during which there are fluctuations in these environmental parameters. Considering that the speed of an acoustic wave can also be influenced by these parameters, it would be useful to conduct a detailed study of how the probability of location and the positioning error evolve over the year.

\section{Availability of supporting data}

The data set supporting the results of this article is included within the article (and its additional files) and is not available.

\section{Abbreviations \\ dGPS: differential GPS; HPE: horizontal position error; TDOA: time difference of arrival; VPS: VEMCO Positioning System; VRAP: VEMCO Radio-Acoustic Positioning.}

\section{Competing interests}

The authors declare that they have no competing interests.

\section{Authors' contributions}

RR designed this study, worked on the data acquisition in the field and the interpretation of the data and wrote the manuscript. JB led the data analysis and participated in drafting the manuscript. CA and LT helped to design the study and draft the manuscript. FS and SS performed the post-processing and gave final approval of the version to be published. EDO participated in the study design and gave final approval of the version to be published. All authors have read and approved the final manuscript.

\section{Acknowledgements}

The authors thank Tiphaine Peroux for her assistance in the field, Yann Le Coarer for his help with dGPS measurements and Maxime Logez from Irstea Aix-en-Provence for his advice. Our thanks are also extended to Electricité de France, which manages the Treignac hydroelectric dam and the Bariousses reservoir.

\section{Author details}

${ }^{1}$ EDF R\&D, LNHE Departement, HYNES (Irstea - EDF R\&D), 6 Quai Watier, Chatou Cedex 78401, France. ${ }^{2}$ Irstea, UR HYAX, HYNES (Irstea - EDF R\&D), 3275 Route de Cézanne CS 40061, Aix en Provence Cedex 5 13182, France. ${ }^{3}$ VEMCO, 20 Angus Morton Drive, Bedford, Nova Scotia B4B OL9, Canada.

Received: 30 July 2013 Accepted: 18 November 2013

Published: 6 January 2014

\section{References}

1. How JR, De Lestang S: Acoustic tracking: issues affecting design, analysis and interpretation of data from movement studies. Mar Fresh Res 2012, 63:312-324.

2. Heupel MR, Semmens JM, Hobday AJ: Automated acoustic tracking of aquatic animals: scales, design and deployment of listening station arrays. Mar Fresh Res 2006, 57:1-13.

3. Cooke SJ, Hinch SG, Lucas MC, Lutcavage M: Biotelemetry and biologging. In Fisheries techniques. 2012th edition. Edited by Zale AV, Parrish DL, Sutton TM. Bethesda: AFS; 2012:819-881.

4. Lucas MC, Baras E: Methods for studying spatial behaviour of freshwater fishes in the natural environment. Fish Fish 2000, 1:283-316.

5. Ehrenberg JE, Steig TW: Improved techniques for studying the temporal and spatial behavior of fish in a fixed location. ICES J Mar Sci 2003, 60:700-706.
6. Bergé J, Capra H, Pella H, Steig T, Ovidio M, Bultel E, Lamouroux N: Probability of detection and positioning error of a hydro acoustic telemetry system in a fast-flowing river: intrinsic and environmental determinants. Fish Res 2012, 125-126:1-13.

7. Espinoza M, Farrugia TJ, Webber DM, Smith F, Lowe CG: Testing a new acoustic telemetry technique to quantify long-term, fine-scale movements of aquatic animals. Fish Res 2011, 108:364-371.

8. Niezgoda G, Benfield M, Sisak M, Anson P: Tracking acoustic transmitters by code division multiple access (CDMA)-based telemetry. Hydrobiologia 2002, 483:275-286.

9. Andrews KS, Tolimieri N, Williams GD, Samhouri JF, Harvey CJ, Levin PS: Comparison of fine-scale acoustic monitoring systems using home range size of a demersal fish. Mar Biol 2011, 158:2377-2387.

10. Ehrenberg JE, Steig TW: A method for estimating the 'position accuracy' of acoustic fish tags. ICES J Mar Sci 2002, 59:140-149.

11. Clements S, Jepsen D, Karnowski M, Schreck CB: Optimization of an acoustic telemetry array for detecting transmitter-implanted fish. North Am J Fish Manage 2005, 25:429-436.

12. Connolly JA: Assessing factors that influence position accuracy in a hydroacoustic telemetry system. Master's thesis. Guelph University; 2012.

13. Understanding HPE in the VEMCO Positioning System (VPS), V1.0, September 27, 2013. Retrieved on September 27, 2013 from [http://vemco.com/wpcontent/uploads/2013/09/understanding-hpe-vps.pdf]

14. Dean MJ, Hoffman WS, Armstrong MP: Disruption of an Atlantic cod spawning aggregation resulting from the opening of a directed gill-net fishery. North Am J Fish Manage 2012, 32:124-134.

15. Espinoza M: Site fidelity, movements and habitat use of gray smooth-hound sharks, Mustelus californicus (Gill 1863), in a newly restored estuarine habitat. Master's thesis. California State University; 2010.

16. Espinoza M, Farrugia TJ, Lowe CG: Habitat use, movements and site fidelity of the gray smooth-hound shark (Mustelus californicus Gill 1863) in a newly restored southern California estuary. J Exp Mar Biol Ecol 2011, 401:63-74.

17. Furey NB, Dance MA, Rooker JR: Fine-scale movements and habitat use of juvenile southern flounder Paralichthys lethostigma in an estuarine seascape. J Fish Biol 2013, 82:1469-1483.

18. Smith NJ: The effect of seabed slope and other environmental variables on the movement patterns of the giant pacific octopus (Enteroctopus dofleini). Master's thesis. Alaska Pacific University; 2012.

19. Steel AE, Sandstrom PT, Brandes PL, Klimley PA: Migration route selection of juvenile Chinook salmon at the Delta Cross Channel, and the role of water velocity and individual movement patterns. Environ Biol Fish 2012, 96:215-224.

20. Thums M, Whiting SD, Reisser JW, Pendoley KL, Pattiaratchi CB, Harcourt RG, McMahon CR, Meekan MG: Tracking sea turtle hatchlings - a pilot study using acoustic telemetry. J Exp Mar Biol Ecol 2013, 440:156-163.

21. Watson DF, Philip GM: A refinement of inverse distance weighted interpolation. Geo-Processing 1985, 2:315-327.

22. R Core Team: R: A Language and Environment for Statistical Computing. Vienna, Austria: R Foundation for Statistical Computing; 2012. URL http://www.R-project.org/. ISBN 3-900051-07-0.

23. Scheel D, Bisson L: Movement patterns of giant Pacific octopuses, Enteroctopus dofleini (Wulker, 1910). J Exp Mar Biol Ecol 2012, 416:21-31.

24. Bisson $\mathrm{L}$ : The effect of environmental variables on the movements of the giant pacific octopus. Master's thesis. Alaska Pacific University; 2011.

25. Pourriot R, Meybeck M: Limnologie générale. Paris: Masson; 1995.

doi:10.1186/2050-3385-2-1

Cite this article as: Roy et al:: Testing the VEMCO Positioning System: spatial distribution of the probability of location and the positioning error in a reservoir. Animal Biotelemetry 2014 2:1. 